\title{
Validation and reliability analysis of the Portuguese language version of Needs of Parents Questionnaire
}

\author{
Pedro L. Ferreira, ${ }^{1}$ Elsa Melo, ${ }^{2}$ Gina Reis, ${ }^{3}$ Débora F. Mello ${ }^{4}$
}

\begin{abstract}
Objective: To describe the procedures followed for the validation and reliability analysis of the Portuguese version of the Needs of Parents Questionnaire in the context of pediatric hospitalization in Portugal.

Methods: This is a descriptive study based on procedures for the cultural and linguistic adaptation of health measurement tools. The validation was performed on a sample of 870 parents of hospitalized children in pediatrics departments from four hospitals in Portugal, with ages ranging from 2 days to 18 years. Content validity was assured by two cognitive debriefing meetings, separately organized with parents and staff. The reliability of the Portuguese version was assessed through reproducibility tests and internal consistency computation.

Results: Using Cronbach's alpha, results from the cognitive debriefing and internal consistency scores were similar to those obtained by the authors of the original version and good for the three subscales, allowing us to state that the questionnaire has the adequate psychometric properties to measure parents' needs. It was well accepted by parents, who valued all needs, especially the need to trust the care provided to their child when they are not present, as well as the need to be trusted and the need for information.

Conclusions: The questionnaire proved to be a valid and reliable measurement instrument to assess the needs of parents during their pediatric hospitalizations. The Portuguese version of the Needs of Parents Questionnaire has been validated.
\end{abstract}

J Pediatr (Rio J). 2010;86(3):221-227: Child, parents, hospitalization

\section{Introduction}

Pediatric hospitalization can be a stressful experience, often leading to suffering for both child and family, associated with separation anxiety, loss of control, and fear of bodily harm and pain. ${ }^{1-3}$ Diagnosis and hospitalization unleash feelings of insecurity, fear and anxiety, triggering an emotional crisis in the family and affecting all members in one way or another. At the onset of disease, reactions of parents and family members to an adverse situation depend on factors ranging from the integrity of family bonds to the transmission of values, considering the culture and society of which they are a part. 3,4
Thus, understanding the responses of children and families to hospitalization and the experience of disease is key to improve quality of care in pediatrics, facilitating adaptation to the new context. The needs that emerge during pediatric hospitalization deserve attention from health care professionals so they can provide increasing benefits and interaction to children. Recent studies show that parents' physical needs tend to be undervalued, compared to emotional ones, 5,6 underscore the financial impact felt by the family, ${ }^{7}$ namely caused by changes to work routines, ${ }^{8}$ and emphasize the importance of proper

1. Professor associado, Agregação, Faculdade de Economia, Universidade de Coimbra (UC), Coimbra, Portugal. Diretor, Centro de Estudos e Investigação em Saúde, UC, Coimbra, Portugal.

2. Doutoranda, Ciências da Saúde. Professora adjunta, Escola Superior de Saúde, Universidade de Aveiro (UA), Aveiro, Portugal.

3. Mestre, Ciências de Enfermagem. Enfermeira especialista, Saúde Infantil e Pediátrica, Hospital Pediátrico de Coimbra, Coimbra, Portugal.

4. Professora associada, Departamento de Enfermagem Materno Infantil e Saúde Pública, Escola de Enfermagem, Universidade de São Paulo (USP), Ribeirão Preto, SP, Brazil.

No conflicts of interest declared concerning the publication of this article.

Suggested citation: Ferreira PL, Melo E, Reis G, Mello DF. Validation and reliability analysis of the Portuguese language version of Needs of Parents Questionnaire. J Pediatr (Rio J). 2010;86(3):221-227.

Manuscript submitted Apr 02 2009, accepted for publication Feb 242010

doi:10.2223/JPED.2001 
information and communication. ${ }^{7-13}$ Likewise, for parents, the negotiation of care, taking their needs into consideration, contributes to adaptation or to the opportunity of playing parental roles, preparing them for care during their child's hospitalization. ${ }^{14,15}$

The needs of parents of hospitalized children are considered by the Needs of Parents Questionnaire (NPQ), developed by Icelander Gudrún Kristjánsdóttir to assess how parents perceive needs emerging from the hospitalization of a child, as well as the importance of those needs and how well they are met.6,16 The questionnaire is an important tool, enabling more advanced practices on the part of health care professionals, focused on the child and their families, based on effective participation of parents in health care processes. The conceptual structure of the questionnaire was based on an extensive literature review and interviews with parents and health care professionals about worries, needs, reactions and sentiments felt during the hospitalization of a child. The current version consists of 51 needs, divided into the following categories: need to trust; need to feel they are trusted; need for information; need for support and guidance; need for physical and human resources; needs of the child and other family members. The needs are analyzed from three points of views: importance of needs, fulfillment of needs, and independence from hospital.

The objective of this study was to describe the procedures followed for the validation and reliability analysis of the Portuguese version of the NPQ in the context of pediatric hospitalization in Portugal.

\section{Method}

Procedures for the cultural and linguistic adaptation of health measurement tools were followed to validate and analyze the accuracy of the Portuguese version of NPQ. ${ }^{11,12}$ The process began by requesting authorization from the authors of NPQ to translate the scales, as well as for clarification regarding methodological procedures. After receiving formal authorization from Gudrún Kristjánsdóttir for the questionnaire for parents, and from Linda Shields for the questionnaire for professionals, the original English language version began to be translated into Portuguese. The classic successive forward-backward translation method was used until there was consensus among the translators about pre-versions.

Two independent professional translators provided the translations, both native speakers of Portuguese with in-depth knowledge of the English language. The two translations were merged into a single document, later back-translated to the original language by two translators who are native speakers of English. The two final English versions were later compared to each other and to the original version to ascertain their equivalence and the consensus among translators.
Face validity was checked through two panels, one consisting of laypersons (six parents of hospitalized children) and another of experts (six health care professionals). For both panels, cognitive debriefing was used to assess clarity, understanding, cultural relevance, inclusion of all concepts, and redundancy of items used. After beginning the session, both panels followed the same method, though it should be clear that the structure of the questionnaire (items and answer options) would not change, and only descriptions of needs would be subject to possible changes. Questionnaires were handed out, and panel members were reminded that the researchers were more interested in how the questions were phrased than in their answers.

To ensure the internal coherence of the questionnaire, Cronbach's alpha coefficient was used for the importance, fulfillment and independence subscales. Though the independence subscale allowed for dichotomous answers, we chose to follow the steps of other authors who worked with the instrument and use Cronbach's alpha coefficient for all three subscales.

A sequential random sample comprised of 870 parents of children hospitalized in pediatrics services of four Portuguese hospitals, two children's hospitals (Hospital Pediátrico de Coimbra, Coimbra; Hospital de Maria Pia, Porto) and two district hospitals with pediatrics services (Hospital Infante D. Pedro, Aveiro; Hospital de São Sebastião, Santa Maria da Feira). Face validation and comprehensibility testing were complemented by asking questions to a subset of the sample.

Data collection followed recommended ethical procedures, including authorization from the Boards of Directors and Research Ethics Committees of all hospitals and the free informed consent of all participants.

Contact with parents was customized, performed by two researchers. Parents were included in the sample if they were present and accompanying a hospitalized child, if the child had been hospitalized for 48 hours or more, and if parents could read and write in Portuguese. Parents were excluded if their children were terminal or if, according to the previous assessment of the nurses responsible for the services, they were not emotionally in condition to answer the questionnaire.

\section{Results}

Panels of experts (professionals) and laypersons (parents of hospitalized children) began by filling out the questionnaires, a process which took between 15 and 30 minutes. Overall, sentences were considered easy to understand, with clear semantic structures, and the questionnaire easy to fill out. Later, the questionnaire was analyzed sentence by sentence in terms of the needs of parents; since no problem was found, the text remained unchanged. 
To complement the testing, 210 parents were also questioned about their understanding of the questions and how they reflected the way they felt, their needs and their fulfillment. Over 90.0 percent of parents answered they had understood all or most questions, that sentences identified well or very well the needs they perceived while their children were hospitalized, and that their own answers reflected their expectations regarding the hospital and their satisfaction with hospital services. No significant differences were found among the opinions of adults accompanying hospitalized children.

Cronbach alpha coefficients found for internal coherence were high, ranging from 0.911 for the importance scale to 0.947 and 0.952 , respectively, for the fulfillment and independence scales. Test-retest for a group of 30 parents, performed by requesting that the questionnaire be filled out at two separate points in time, with intervals ranging from 8 to 20 days, found the following values: 0.782 for importance, 0.876 for fulfillment, and 0.901 for independence.

The sample comprised 870 parents of hospitalized children, with a response rate of 66 percent, above the 55 percent found by the authors. ${ }^{9}$ Table 1 presents the distribution of elements by the four hospitals participating in this study, by inpatient service, and by sociodemographic characteristics.

The data shows caregivers were most often female $(85.0 \%)$, especially mothers $(84.2 \%)$, similar to other studies of the kind. $2,9,17$ On average, adults accompanying children were 33.2 years old, most (87.2\%) were married or in stable relationships, 21.2 percent had not completed primary school and 15.5 percent had a college degree. As for socioeconomic status, 43.5 percent were of average level, 49.6 were of very good or good level, and only 6.9 percent were of poor or bad level.

On average, children were 4 years old; $50.4 \%$ percent were younger than 2 years old and 8.6 percent were older than 11. As for gender, male children were found slightly more often. Mean length of hospitalization was 4.5 days.

Parents perceived 34.5 percent of children as having average health and 6.5 percent having poor health. Most children $(70.8 \%)$ lived within $50 \mathrm{~km}$ of the hospital.

\section{Analysis of importance items}

Mean importance values ranged from 48.1 to 96.5 in a scale from 0 to 100 . The items considered least important corresponded to the need for a separate location where parents can be alone and the need for planned meetings with other parents to share and discuss the experience of hospitalization. On other end of the scale, the most important needs were for accurate information about the child's health status; being able to trust that, even when absent, the best medical and nursing care would be provided to their children; and the possibility of staying with the child 24 hours a day.

Ninety two percent of items were considered important or very important by adults accompanying children, 90 percent for mothers and 88 percent for parents. Comparing the answers of these two categories of parents, we found that there is not much difference between them. However, mothers rate the following as slightly more important: being able to care for their children ( $p<0.05)$; flexibility for the needs of parents ( $p<0.05)$; feeling they are needed ( $p<0.007)$; feeling less anxiety ( $<<0.003)$; having health care professionals understand their feelings ( $p<0.04$ ); being able to contact the hospital after discharge ( $p<0.01)$; having a social worker provide information on financial aid ( $p<0.01$ ); being able to explain aspects of the hospitalization to family members, friends and others ( $p<0.007)$; and receiving the aid and support they need to become aware of their own needs.

Mothers also claim as slightly more important that bathrooms be provided to adults accompanying children ( $p<0.03$ ); that teachers, educators or cultural entertainers be available to help motivate their children and maintain their development and learning ( $p<0.01)$; and that a staff member be assigned exclusively to caring for their child's needs ( $p<0.003)$. Finally, mothers rate as slightly more important that they not be considered responsible for their child's illness $(p<0.03)$, and that same professionals treat their children most of the time $(p<0.007)$.

\section{Analysis of fulfillment items}

On a scale from 0 to 100 , mean fulfillment of needs and occurrence of situations ranged from 21.0 to 93.6. The least frequent situations were planned meetings with other parents to share and discuss the experience of the child's hospitalization, meeting other parents who went through similar experiences, knowing a nurse would accompany the child after discharge, being able to contact a social worker regarding financial aid, and knowing the child would have extra classes and activities so they would not fall behind on their studies and development. On the other hand, the most frequent situations were being able to stay with the child 24 hours a day, if desired; being able to care for them and sleep in the same room; being able to trust that the child would receive the best medical and nursing care available even in their absence; feeling they are important and contribute to the well-being of the child; and feeling that health care professionals trusted them to care for their child in the hospital as well.

Interestingly, 11 out of the 51 needs listed in NPQ had fulfillment greater than 80 percent, and only four featured statistically significant different opinions between mothers and fathers. The fact that mothers gave more positive scores for various situations that happened during their child's hospitalization is also noteworthy. 
Table 1 - Sample characteristics $(n=870)$

\section{Variables}

Hospital

Infante D. Pedro, Aveiro

Maria Pia, Porto

Pediátrico, Coimbra

São Sebastião, Feira

Service

Medicine

Surgery

Medical specialties

Surgical specialties

Intensive care unit

Neonatology

Gender of adult accompanying child

Female

Male

Age of adult accompanying child

From 16 to 20 years old

From 21 to 30 years old

From 31 to 40 years old

Over 40 years old

Mean \pm standard deviation

Relationship to child

Mother

Father

Other

Family status of adult accompanying child

Married/stable relationship

Single

Widowed

Divorced/separated

Educational level of adult accompanying child

Incomplete primary school

Complete primary school

High school

College

Socioeconomic level of adult accompanying child (Graffar scale)

Very good

Good

Reasonable

Diminished

Bad

Gender of child

Female

Male

Age of child

2 years old or less

3 to 6 years old

7 to 11 years old

12 to 16 years old

Mean \pm standard deviation (years)

Parents' perception of child's health

Poor

Average

Good

Very good

Excellent

Length of hospitalization

2 days to 1 week

1 week to 15 days

More than 15 days

Mean (days)

Distance from hospital

$\leq 50 \mathrm{~km}$

$>51 \mathrm{~km}$ n (\%)

$174(20.0)$

$260(29.9)$

$210(24.1)$

$226(26.0)$

499 (57.4)

$177(20.3)$

18 (2.1)

$61(7.0)$

30 (3.4)

85 (9.8)

737 (85.0)

130 (15.0)

25 (2.9)

271 (31.9)

441 (51.9)

113 (13.3)

$33.2 \pm 6.7$

$731(84.2)$

130 (15.0)

$7(0.8)$

$751(87.2)$

55 (6.4)

$6(0.7)$

49 (5.7)

181 (21.2)

269 (31.5)

271 (31.8)

87 (15.5)

64 (10.9)

227 (38.7)

255 (43.5)

39 (6.7)

$1(0.2)$

272 (41.5)

384 (58.5)

$428(50.4)$

181 (21.3)

167 (19.7)

$73(8.6)$

$4.0 \pm 4.2$

42 (6.5)

224 (34.5)

244 (37.5)

89 (13.7)

$51(7.8)$

$678(78.2)$

101 (11.7)

$88(10.1)$

4.5

$566(70.8)$

$234(29 ; 2)$ 
Comparing mean importance values to the occurrence and fulfillment of various needs, we find that needs rated by parents as most important are also the most frequent, and therefore those most fulfilled for parents of hospitalized children. The graph in Figure 1 shows this relationship, with needs represented as dots; coordinates represent mean importance and fulfillment of need.

Joint analysis of both distributions, of importance and fulfillment of needs, shows that six of the ten needs rated as most important always occurred during hospitalization. They were: being able to trust that, even when absent, the child would receive the best medical and nursing care available; being able to stay with the child 24 hours a day; remaining informed about every treatment the child receives; being to sleep in the child's room; and having hope about the child's health status. These are, perhaps, the needs that best justify parents' general satisfaction with their child's hospitalization. We should also stress that no aspect rated as very important by parents goes unfulfilled.

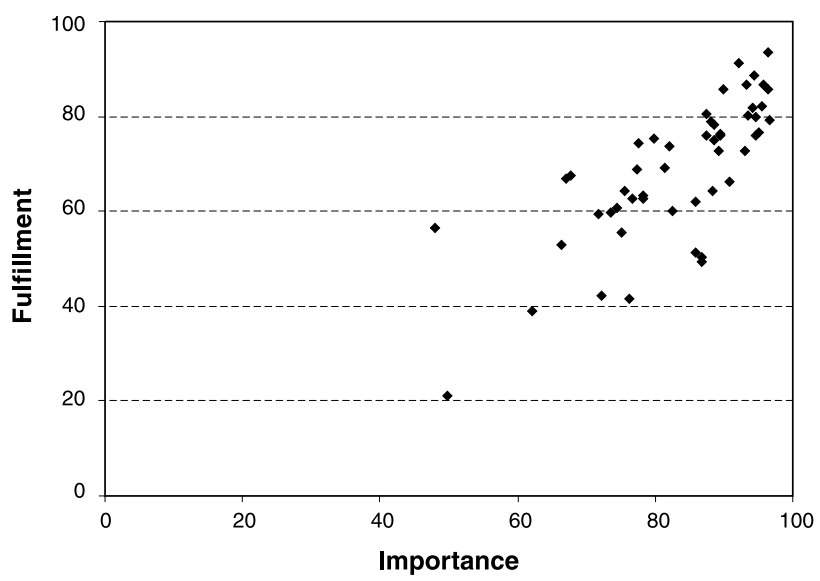

Figure 1 - Relationship between importance and fulfillment of needs

\section{Analysis of independence items}

The percentage of affirmative answers regarding the role of the hospital in providing support to the needs of parents ranged from 69.2 to 95.9 percent. Parents felt the hospital should not have the initiative in planning meetings with other parents to share and discuss the experience of pediatric hospitalization or provide a location at the service where parents can be alone. On the other hand, the hospital was considered fully responsible for providing information about possible prognoses, counseling while the child is prepared to be discharged and about special care to be provided to the child, information about their health status and how the disease and the treatment will impact their growth and development, among others.
Overall, mothers and fathers do not differ much regarding the responsibility they attribute to the hospital for helping them meet their needs. Exceptions are planning for discharge $(p<0.02)$, the presence of a teacher, educator or cultural entertainer $(p<0.04)$, for which mothers attribute more responsibility to the hospital than fathers. They also rate the hospital's role in maintaining their hope about their child's health status $(p<0.03)$, trusting in parents to care for the children at the hospital as well ( $p<0.02)$, making them feel they are needed ( $p<0.007)$, not blaming them for their child's disease $(p<0.04)$, and being able to trust that, even when absent, their children would receive the best care available $(p<0.006)$.

\section{Analysis of grouped items}

When importance items are aggregated, it becomes clear fathers and mothers of hospitalized children attribute high levels of importance to the need for trust, the need for information, and the need to be trusted. In terms of how well those needs are met, we find the aspects listed above are indeed met. Finally, in terms of independence and the role of the hospital in meeting those needs, the need for information stands out. Mean values are presented in Table 2.

This table allows us to conclude that, in relation to importance items, parents' perceptions are positively correlated with the how their needs are met as well as to request that hospitals help meet those needs.

\section{Discussion}

Using Cronbach's alpha, results from the cognitive debriefing and internal consistency scores were similar to those obtained by the authors of the original version 6,16 and good for the three subscales, allowing us to state that the questionnaire has the adequate psychometric properties to measure parents' needs. We should also stress that the questionnaire has been used in other studies and other countries: in Iceland, 6,18 Canada (both in English and in French), ${ }^{9}$ Sweden, ${ }^{5,10}$ England, ${ }^{9}$ and Greece. ${ }^{2}$

Overall, parents valued all needs, especially the need to trust the care provided to their child when they are not present, as well as the need to be trusted and the need for information.

While a child is hospitalized, the care usually provided by parents becomes the partial responsibility of health care professionals. According to some studies, nurses have trouble trusting in the capacity of parents, perhaps because they are afraid of inverting the care process or loss of professional identity. 4,19-22 The results of this study show the importance parents attribute to being trusted by professionals in the care they usually provide to their children, to wit, hygiene, feeding and comfort. 
Table 2 - Mean aggregate values (total sample and by sex of adult accompanying child)

\begin{tabular}{|c|c|c|c|c|c|}
\hline Dimensions & Total & Mothers & Fathers & $\mathbf{t}$ & $\mathbf{p}$ \\
\hline \multicolumn{6}{|l|}{ Importance } \\
\hline$A$ & 96.1 & 96.5 & 94.5 & 2.11 & NS \\
\hline$B$ & 86.3 & 86.9 & 82.9 & 2.86 & 0.004 \\
\hline C & 89.2 & 89.6 & 87.3 & 2.49 & 0.013 \\
\hline $\mathrm{D}$ & 81.1 & 81.5 & 79.1 & 2.26 & 0.024 \\
\hline$E$ & 78.3 & 78.8 & 76.1 & 2.36 & 0.018 \\
\hline $\mathrm{F}$ & 82.6 & 83.2 & 79.5 & 2.93 & 0.003 \\
\hline \multicolumn{6}{|l|}{ Fulfillment } \\
\hline A & 86.1 & 86.6 & 83.3 & 1.83 & NS \\
\hline $\mathrm{B}$ & 78.7 & 79.3 & 75.7 & 2.22 & 0.027 \\
\hline C & 70.3 & 70.8 & 67.4 & 2.01 & 0.045 \\
\hline $\mathrm{D}$ & 64.0 & 64.3 & 62.7 & 1.05 & NS \\
\hline $\mathrm{E}$ & 63.6 & 63.9 & 61.7 & 1.60 & NS \\
\hline $\mathrm{F}$ & 71.2 & 71.6 & 69.2 & 1.63 & NS \\
\hline \multicolumn{6}{|l|}{ Independence } \\
\hline$A$ & 92.1 & 92.9 & 88.1 & 1.85 & NS \\
\hline$B$ & 85.7 & 86.6 & 80.3 & 2.37 & 0.019 \\
\hline $\mathrm{C}$ & 93.4 & 93.7 & 91.5 & 1.32 & NS \\
\hline $\mathrm{D}$ & 87.1 & 87.6 & 84.1 & 1.93 & NS \\
\hline$E$ & 86.7 & 87.1 & 84.8 & 1.36 & NS \\
\hline $\mathrm{F}$ & 87.1 & 87.6 & 84.7 & 1.23 & NS \\
\hline
\end{tabular}

$\mathrm{A}=$ need to trust; $\mathrm{B}=$ need to feel they are trusted; $\mathrm{C}=$ need for information; $\mathrm{D}=$ need for support and guidance; $\mathrm{E}=$ need for physical and human resources;

$\mathrm{F}=$ needs of the sick child and other family members; NS = not significant.

Parents also place high value on the information provided by health care professionals about their child's health status, diagnostic examinations, treatment, and prognosis. This matches the findings of other researchers, who consider the information provided by health care professionals to parents as critical to lower their anxiety and insecurity, contributing to the well-being of the child and better performance of parental roles. ${ }^{5,15-17}$

Globally, parents say their needs are met during their child's hospitalization, though they attribute to hospitals the role of helping them meet those needs.

\section{Conclusion}

In conclusion, the questionnaire proved to be a valid and reliable measurement instrument to assess the needs of parents during their pediatric hospitalizations.

This study broadens the knowledge of the needs of parents are they accompany sick children in hospital environments. It underscores the importance of the needs of parents in pediatric health care contexts to provide high quality, humane care.

\section{References}

1. Algren C. Cuidado centrado na família da criança durante a doença e a hospitalização. In. Hockernberry $M \mathrm{~J}$. Wong: fundamentos de enfermagem pediátrica. Mosby: Rio de Janeiro; 2006. p. 637-705.

2. Kyritsi $H$, Matziou V, Perdikaris $P$, Evagelou H. Parent's needs during their child's hospitalization. Nursing Gr. 2005;23:1-9.

3. Vessey J. Children's psychological responses to hospitalization. In: Fitzpatrick J J. Annual review of nursing research. New York: Springer Publishing Company; 2003. p. 173-201.

4. Jorge A. Família e hospitalização da criança: (re)pensar o cuidar em enfermagem. Loures: Lusociência; 2004.

5. Shields L, Kristensson-Hallström I, O'callaghan M. An examination of the needs of parents of hospitalised children: Comparing parents' and staff's perceptions. Scand J Caring Sci. 2003;17:176-84.

6. Kristjánsdóttir G. Perceived importance of needs expressed by parents of hospitalized 2 to 6 year olds. Scand J Caring Sci. 1995; 9:95-103.

7. Callery P. Paying to participate: financial, social and personal costs to parents of involvement in their children's care in hospital. J Adv Nurs. 1997;25:746-52.

8. Shields $L$. A review of the literature from developed and developing countries relating to the effects of hospitalization on children and parents. Int Nurs Review. 2001;48:29-37.

9. Shields L, Hunter J, Hall J. Parents' and staff's perceptions of parental needs during a child's admission to hospital: an English perspective. J Child Health Care. 2004;8:9-33. 
10. Shields L, Kristensson-Hallstrom I. We have needs too: parental needs during a child 's hospitalization. Online Braz J Nurs. 2004;3: e. http://www.uff.br/nepae/siteantigo/objn303shieldsetal.htm. Access: 30/04/2006.

11. Dunckley $M$, Hugles R, Addington $H$ J, Higginson I J. Language translation of outcome measurements tools: views of health professionals. Int J Palliat Nurs. 2003;9:49-55.

12. Hunt SM. Cross cultural comparability of measures and other issues related to multicountry studies. $\mathrm{Br} \mathrm{J}$ Med Economics. 1993;6:27-34.

13. Ferreira $P$, Marques F. Avaliação psicométrica e adaptação cultural e linguística de instrumentos de medição em saúde: princípios metodológicos gerais. Coimbra: Centro de Estudos e Investigação em Saúde da Faculdade de Economia da Universidade de Coimbra; 1998.

14. Subtil C, Fonte A, Relvas A. Impacto na família da doença grave/ crônica em crianças: inventário de respostas à doença dos filhos. Psiquiatr Clin. 1995;16:241-50.

15. Reis G. Expectativas dos pais durante a hospitalização da criança [dissertação]. Porto: Universidade do Porto; 2007.

16. Kristjánsdóttir G. A study of the needs of parents of hospitalized 2 to 6 year old children. Issues Compr Pediatr Nurs. 1991;14:49-64.
17. Sabatés A, Borba R. As informações recebidas pelos pais durante a hospitalização do filho. Rev Latino Am Enfermagem. 2005;13:968-73.

18. Bragadottir H. A descriptive study of the extent to which selfperceived needs of parents are met in pediatric units in Iceland. Scand J Caring Sci. 1999;13:201-7.

19. Hallstron I, Runeson I, Elander G. Observed parental needs during their child's hospitalization. J Pediatr Nurs. 2002;17:141-8.

20. Melnyk B, Alpert-Gilles L, Feinstein N, Crean H. Creating opportunities for parent empowerment: program effects on the mental health/coping outcomes of critically iII young children and their mothers. Pediatrics. 2004;113:597-607.

21. Brown J, Ritchie J. Nurses' perceptions of parent and nurse roles in caring for hospitalized children. Children Health Care. 1999;19:28-36.

22. Coyne I. Parental participation in care: a critical review of the literature. J Adv Nurs. 1995;21:716-22.

Correspondence:

Pedro L. Ferreira

Tel.: +351239790507

E-mail: pedrof@fe.uc.pt 